\title{
Comparison of E test and Disk Diffusion Test for Antibiotic Resistance Test- ing of Enterotoxigenic and Non-Enterotoxigenic Bacteroides fragilis Isolated From Stools
}

\author{
Mohammad Taghi Akhi ${ }^{1,2,{ }^{*}, \text { Reza Ghotaslou }}{ }^{2}$, Mahnaz Shirinzadeh ${ }^{2}$, Tahereh Pirzadeh ${ }^{2}$, \\ Mohammad Naghavi Behzad ${ }^{3}$ \\ ${ }_{2}^{1}$ Research Center of Infectious and Tropical Diseases, Tabriz University of Medical Sciences, Tabriz, IR Iran \\ ${ }_{3}^{2}$ Department of Bacteriology and Virology, School of Medicine, Tabriz University of Medical Sciences, Tabriz IR Iran \\ ${ }^{3}$ Medical Faculty, Tabriz University of Medical Science, Tabriz, IR Iran \\ ${ }^{*}$ Corresponding author: Mohammad Taghi Akhi, Research Center of Infectious \& Tropical Diseases, Tabriz University of Medical Sciences, Tabriz, IR Iran. Tel/Fax: +98-4113364661, E- \\ mail:m_t_akhi@yahoo.com.
}

Received: December 17, 2012; Revised: March 09, 2013; Accepted: March 11, 2013

\begin{abstract}
Background: Enterotoxigenic Bacteroides fragilis (ETBF) are one of the most important anaerobic bacteria which cause diarrhea in human beings. A bft gene is coded for enterotoxin production called fragilysin. Most of them have acquired resistance to antianaerobic bacteria agent like other facultative anaerobic bacteria. E test and different dilution methods are usually performed for antimicrobial susceptibility determination of $B$. fragilis.

Objectives: The aims of this study are to recognize ETBF by PCR method and also to evaluate efficiency the disk diffusion method (DDM) in comparison with the E tests for antimicrobial susceptibility of B. fragilis isolates.

Materials and Methods: bft gene was detected among 157 B. fragilis isolated from patients and healthy individuals by PCR. Antimicrobial susceptibility of all isolates was determined by DDM and E tests methods.

Results: Nineteen (12.1\%) B. fragilis containing bft gene from diarrheic $(n=14)$ and nondiarrheic $(n=5)$ feces were detected among $157 B$. fragilis isolates. The highest resistance for ciprofloxacin, cefotaxim, cefoxitin with DDM and E test were 100\%, 60\%, and 65\% respectively, while the lowest resistance in two methods was obtained for imipenem, piperacillin / tazobactam, and metronidazol. 100\% agreement for some of antibiotics such as imipenem $(\mathrm{P} \leq 0.05)$, and no correlation for others were observed among the antimicrobial susceptibility results obtained by the two methods $(\mathrm{P} \geq 0.05)$.

Conclusions: The presence of bft gene in B. fragilis isolates would not certainly result in diarrhea among patients. There is not enough accordance between DDM and Swedish E tests for antimicrobial susceptibility of B. fragilis for some antibiotics, although in other cases a good agreement was observed.
\end{abstract}

Keywords: Bacteroides fragilis; Antibiotic Resistance; Disk Diffusion Antimicrobial Tests

\section{Background}

Bacteroides fragilis is one of the most important anaerobic non-spore-forming bacteria among human body's anaero-biomicrofloras. This bacterium has an important role in causing human's diarrhea and other infections such as post surgery infections, septicemia, gynecological, skin and soft tissue infections, brain abscess and meningitis (1). Enterotoxin produced by $B$. fragilis is an important factor resulting in diarrhea which is controlled by bft gene. Enterotoxin or fragilisin is a zinc-dependent meta-protease with molecular weight of 20000 Da. This toxin causes the intestinal cells to lose fluids by removing epithelial barriers (2).

An assay using HT291C1 cells facilitated the detection of this toxin in research laboratories, but PCR assay is a valuable technique for detecting DNA sequences specific to organisms or for individual genes (3). In general, PCR assays are more objective than cell culture assays for detecting toxins. B. fragilis such as facultative anaerobic bacteria is capable of gaining resistance against different antibiotics, and in this case it takes the first place among anaerobic bacteria (4). Determining resistance pattern of these bacteria is completely important for treating resulted infections, and is usually conducted by agar dilution or E test method based on guidelines of CLSI $(5,6)$.

Disk diffusion method (DDM) is based on the inhibited growth zones, when fixed concentrations of an antimicrobial compound diffuse from the antibiotic disks into

Implication for health policy/practice/research/medical education:

$B$. fragilis isolated from patients with diarrhea contain bft gene, but its presence in different isolates would not certainly result in diarrhea among patients. In addition the results of DDM for anaerobes even for fast growing anaerobe bacteria such as $B$. fragilis should be confirmed by other reliable ones like Swedish E test or agar dilution methods.

Copyright (C) 2013, Ahvaz Jundishapur University of Medical Sciences; Licensee Kowsar Ltd. This is an Open Access article distributed under the terms of the Creative Commons Attribution License (http://creativecommons.org/licenses/by/3.0), which permits unrestricted use, distribution, and reproduction in any medium, provided the original work is properly cited. 
agar plate, which has formerly been inoculated with the test organism. The inhibition zones around the disks are measured after suitable incubation and interpreted as sensitive, intermediate, and resistant zones $(7,8)$. The epsilometer test (E-test) is the combination of the diffusion and the ability to establish a minimum inhibitory concentration (MIC) or breakpoint result. It is based on diffusion of a preformed antimicrobial gradient from coated plastic strips onto an agar plate inoculated with the test organism $(9,10)$.

DDM is not approved by CLSI for this bacterium and criteria for result interpretation are not determined yet. Since agar dilution test is a time consuming and expensive one, most of researchers are making efforts to standardize disk diffusion method for evaluating anaerobic bacteria's antibiotic sensitivity such as that of the $B$. fragilis. Barry et al. evaluated sensitivity of $B$. fragilis to nine antibiotics by disk diffusion method in 1990 and reported collected results as satisfactory (11). However, other researchers claimed this method as an absolutely improper method for evaluating anaerobic sensitivity (12).

\section{Objectives}

The objectives of this research are to recognize enterotoxigenic $B$. fragilis by PCR method, and also to evaluate efficiency thedisk diffusion method in comparison with the E tests method for antimicrobial susceptibility testing of $B$. fragilis isolates.

\section{Materials and Methods}

One hundred fifty seven B. fragilis strains were isolated from 188 diarrheic and non-diarrheic fecal samples of patients and healthy individuals, and identified by biochemical techniques as described before $(13,14)$. Enterotoxigenic Bacteroid fragilis (ETBF) strains were detected by bft gene detection. DNA extraction- to detect the bft gene, one colony of each isolate grown in reduced blood agar under anaerobic conditions $(\mathrm{CO} 2=10 \%, \mathrm{H} 2=10 \%, \mathrm{~N} 2$ $=80 \%$ ) was suspended in $300 \mu \mathrm{l}$ of ultrapure water, homogenized, boiled for $20 \mathrm{~min}$ and centrifuged at $14000 \mathrm{~g}$, for 10 min. Supernatants were used as templates in PCR reaction performed with following specific primers for amplification of $294 \mathrm{bp}$ fragment (BF1:5'dGACGGTGTATG TGATTTGTCTGAGAGA-3'and BF2: 5'dATCCCTAAGATTTTATTATCCCAAGTA-3') $(15,16)$.

DNA amplifications were performed in $25 \mu \mathrm{l}$ containing $2.5 \mu \mathrm{l}$ of $10 \mathrm{X}$ PCR buffer, $1.25 \mu \mathrm{l}$ of $\mathrm{MgCl} 2(1.5 \mathrm{mM}), 2.0 \mu \mathrm{l}$ of dNTP mixture $(0.2 \mathrm{mM}), 0.25 \mu \mathrm{l}$ of Taq DNA polymerase (0.5 U), $1 \mu \mathrm{l}$ of each primer $(0.4 \mathrm{mM}), 7 \mu \mathrm{l}$ of ultrapure water, and $10 \mu \mathrm{l}$ of DNA template (Concentration of DNA was determined by measuring the ratio of OD values at $260 / 280 \mathrm{~nm}$ ). Amplification was performed in a DNA thermal cycler (Gradient Eppendrof) programmed for $94^{\circ} \mathrm{C}$ (five minutes) followed by 35 cycles of $94^{\circ} \mathrm{C}$ (one minute), $52^{\circ} \mathrm{C}$ (one minute), $72^{\circ} \mathrm{C}$ (one minute), and then $72^{\circ} \mathrm{C}$ (five minutes)

A negative control without template was included in each PCR run. Amplified products were visualized by electrophoresis in $1 \%$ agarose gel in $1 \mathrm{X}$ TBE buffer (1 M Tris, 0.9 $\mathrm{M}$ boric acid, 0.01 M EDTA, $\mathrm{pH} 8.4$ ), at $80 \mathrm{v}$, for two hours. A 100 bp DNA Ladder was used as a molecular mass marker. Gels were stained with ethidium bromide ( $0.5 \mu \mathrm{g}$ ml-1) and photographed on a gel documentation system (UVP, USA) for the analysis of bands (15).

\subsection{Susceptibility Tests}

In disk diffusion technique, the zone inhibition size of antibiotic disks is mostly dependent on antimicrobial concentration, a critical population of organisms and time. These conditions make it unsuitable for testing slow growing organisms. However, anaerobes that grow well within $24 \mathrm{~h}$ seem to be tested by disk diffusion as a screen for resistance (17). In this study we performed sensitivity test for $B$. fragilis isolates based on a modified disc diffusion method for susceptibility testing of fastidious bacteria according to the CLSI guidelines. Since some of anaerobic bacteria do not grow well enough on MullerHinton to permit antimicrobial susceptibility testing, so we decided to use brucella blood agar supplemented with hemin and vitamin K (BBA) for antimicrobial susceptibility testing of $B$. fragilis by $\mathrm{E}$ test and disc diffusion methods (17).

B. fragilis isolates were subcultured on to Columbia agar (Oxoid, UK), containing 5\% (v/v) sheep blood, and were incubated under anaerobic conditions ( $\mathrm{CO} 2=10 \%, \mathrm{H} 2=$ $10 \%, \mathrm{~N} 2=80 \%$ ) at $37^{\circ} \mathrm{C}$ for $48 \mathrm{~h}$. Following incubation, suspensions of pure cultures were prepared in sterile physiological serum, and were adjusted to give inoculums with an equivalent cell density to 0.5 McFarland turbidity standards $(1.5 \times 108 \mathrm{cfu} / \mathrm{mL})$. Cell suspensions were then swabbed evenly onto BBA plates. On each $9 \mathrm{~cm}$ plate containing BBA, E test gradient strip (AB biomeriux, Sweden) of following antibiotics and corresponding disc (Mast Ltd) were applied: amoxicillin/clavulanic acid, imipenem, piperacillin/tazobactam, metronidazol, cefoxitin, cefotaxim, ciprofloxacin, clindamicin, chloramphenicol, rifampin (antibiotic concentration of $\mathrm{E}$ tests and discs are shown in Table 1).

Plates were incubated under anaerobic conditions at $37^{\circ} \mathrm{C}$ for $48 \mathrm{~h}$. The inhibition zones for each antibiotic disk were measured by ruler and were interpreted according to the guidelines recommended for fastidious bacteria by CLSI $(6,18)$. The MIC values were read where the edge of the inhibition ellipse intersected the strip. Readings for each culture were recorded and classified as being resistant or sensitive based on their MIC breakpoints according to the manufacturer's and the CLSI instructions (6). Although we already know that all anaerobic bacteria are resistant to aminoglycosids, to confirm anaerobic origin of isolates we tested gentamicin too.

Antimicrobial resistance of the all $B$. fragilis isolates to 
each of the 11 antimicrobials, using both the agar disk diffusion and E-test methodologies was compared by Fischer exact two-tailed analysis with significance defined at the 95\% level ( $\mathrm{P} \leq 0.05$ ). All statistical analyses were performed using SPSS version 18 software.

\section{Results}

In this study 157 B. fragilis isolates from diarrheic ( $\mathrm{n}=$ $32,20.38 \%)$ and non-diarrheic $(n=125,9.62 \%)$ fecal samples were evaluated for bft gene by PCR. Nineteen (12.1\%) B. fragilis containing bft gene from diarrheic $(n=14)$ and nondiarrheic $(n=5)$ were detected (Figure 1$)$. While there was $100 \%$ agreement for some of antibiotics such as imipenem, ciprofloxacin, rifampin among the results obtained by disk diffusion and $\mathrm{E}$ tests $(\mathrm{P} \leq 0.05)$, no correlation for others were also observed among the results of two methods $(P \geq 0.05)$ (Table 1$)$.

The lowest sensitivity in two methods was detected for ciprofloxacin ( $0 \%$ in E test, and 0\% in DDA). The highest resistance for ciprofloxacin, cefotaxim, cefoxitin with DDA and $\mathrm{E}$ test were $100 \%, 60 \%$, and $65 \%$ respectively, while the lowest resistance in two methods was obtained for imipenem, rifampin, piperacillin/tazobactam, and metronidazol (Table 1$)$.

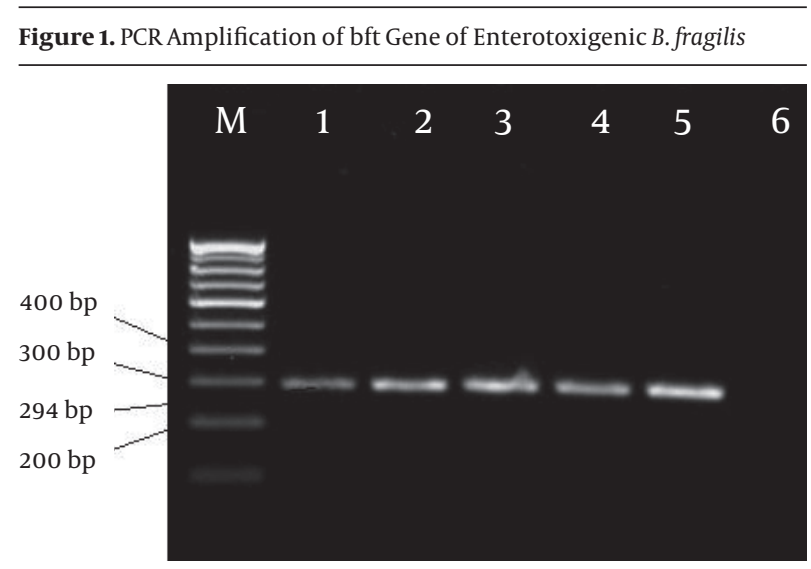

M;100 bp DNA ladder, 6; negative control, 1, 2, 3, 4, 5 are representative of enterotoxigenic $B$. fragilis isolates (294 bp).

Table 1. Susceptibility of Bacteroid fragilis Isolated From Diarrheal and non- Diarrheal Patients and Healthy Individuals Stools by E Test and Disk Diffusion Methods

\begin{tabular}{|c|c|c|c|c|c|c|c|c|}
\hline \multirow[t]{2}{*}{ Antibiotics } & \multirow[t]{2}{*}{$\begin{array}{l}\text { Antibiotic Con- } \\
\text { tent of E tests } \\
\text { Strips, } \mu \mathrm{g} / \mathrm{mL}) \\
(\text { disks, } \mu \mathrm{g})\end{array}$} & \multirow[t]{2}{*}{$\begin{array}{l}\text { ObtainedMIC by E } \\
\text { tests, } \mu \mathrm{g} / \mathrm{mL}\end{array}$} & \multicolumn{2}{|c|}{$\begin{array}{l}\text { Obtained } \\
\text { Results by E } \\
\text { tests }\end{array}$} & \multirow[t]{2}{*}{$\begin{array}{l}\text { Obtained Inhibition } \\
\text { Zone by Disk Diffu- } \\
\text { sion for Different } \\
\text { Isolates, mm }\end{array}$} & \multicolumn{2}{|c|}{$\begin{array}{l}\text { Obtained } \\
\text { Results by } \\
\text { Disk Diffu- } \\
\text { sion }\end{array}$} & \multirow[t]{2}{*}{ Pvalue } \\
\hline & & & $\mathbf{S} \%$ & $\mathbf{R} \%$ & & $\mathbf{S} \%$ & $\mathbf{R} \%$ & \\
\hline $\begin{array}{l}\text { Amoxicillin/Cla- } \\
\text { vulanic acid }\end{array}$ & $0.016-256(20 / 10)$ & $0.5-32$ & 35 & 65 & $17-28$ & 75 & 25 & 0.07 \\
\hline Imipenem & $0.002-32(10)$ & $0.3-1.1$ & 100 & 0 & 32.4 & 100 & 0 & 0.001 \\
\hline $\begin{array}{l}\text { Piperacillin/ } \\
\text { Tazobactam }\end{array}$ & $0.016-256(100 / 10)$ & $0.01-128$ & 95 & 5 & 32.4 & 100 & 0 & 0.04 \\
\hline Metronidazol & $0.016-256(5)$ & $0.2-64$ & 95 & 5 & $15-30.2$ & 93 & 7 & 0.03 \\
\hline Cefoxitin & $0.016-256(30)$ & $\leq 64$ & 0 & 100 & $21-29$ & 35 & 65 & 0.65 \\
\hline Cefotaxim & $0.016-256(30)$ & $\leq 64$ & 0 & 100 & $18-32$ & 40 & 60 & 0.75 \\
\hline Ciprofloxacin & $0.002-32(5)$ & $\leq 32$ & 0 & 100 & 17 & 0 & 100 & 0.001 \\
\hline Clindamicin & $0.016-256(2)$ & $2-16$ & 10 & 90 & $14-25$ & 38 & 62 & 0.65 \\
\hline $\begin{array}{l}\text { Chlorampheni- } \\
\text { col }\end{array}$ & $0.016-256(30)$ & $2-64$ & 45 & 55 & $24-30.2$ & 65 & 45 & 0.55 \\
\hline Rifampin & $0.016-2569(5)$ & $0.03-0.05$ & 100 & 0 & $20-26$ & 100 & 0 & 0.001 \\
\hline Gentamicin $^{\mathrm{a}}$ & $0.016-256(10)$ & $\leq 128$ & 0 & 100 & 2 & 0 & 100 & 0.001 \\
\hline
\end{tabular}

${ }^{\mathrm{a}}$ Anaerobic are genetically resistant to aminoglycosides

\section{Discussion}

B. fragilis has been known as a cause for diarrhea in animals and humans. Although they usually form $1-2 \%$ of the normal human intestinal flora, they may play role in extra intestinal infections. Recently ETBF isolation from healthy children and adults' feces and also from those with diarrhea was reported (14). Researchers have discov- ered B. fragilis enterotoxin directly from a part of feces sample whose culture hadpositive results for ETBF (14) and different studies in Brazil reported 1.5-3\% ETBF among stool samples (19). In other studies high numbers of ETBF have been reported in different points of the world (3, 20), for instance Kato et al.(1996) reported a percentage 
of $18.5 \%$ in Japan, while it was about $14 \%$ in Poland and Holland (21).

Other researchers have reported isolation percentage of ETBF as $6-12 \%$ in the USA, $11 \%$ in Italy, $12 \%$ in Sweden, and $2-6 \%$ in Bangladesh (15). Also studies showed that regardless of being diarrheal or non-diarrheal one can host ETBF organisms as carrier and natural flora of intestine (15). In this study, totally $157 \mathrm{~B}$. fragilis including $32 \mathrm{~B}$. fragilis of diarrheal feces and 125 cases of non-diarrheal feces were studied by PCR to find out the bft gene. Nineteen cases (12.1\%) including bft gene were discovered in diarrheal feces (14 cases) and non-diarrheal feces (5 cases). These results are in accordance with many obtained results in the world (15), however are in contrast with the results reported in Brazil which are significantly lower than this number (19).

Due to lack of scientific information about occurrence of ETBF among Tabriz population, it is not possible to compare the findings of this research with previously obtained results. Observation of ETBF among B. fragilis islolates from feces samples of non-diarrheal persons could prove the presence of healthy carriers as infection resources for susceptible people. It is probable that no toxin would be produced in spite of presence of bft gene, due to environmental factors.

Previously for routinely curing infections caused by anaerobic bacteria, physicians were selecting antimicrobial materials based on experiences on that region's medical sciences, but nowadays selection of antimicrobial materials has been difficult due to the increase in drug resistance among facultative and obligate anaerobic bacteria (4). As a result it is inevitable to perform tests of bacteria sensitivity to antibiotics in in-vitro method.

Many approaches were invented for this goal, among which the disk diffusion method is acceptable among most of microbiologists due to its high speed and ease of performance, and its accessibility. But it seems that this method lacks acceptable quality in anaerobic cases (4). In the second part of this study, the more practical and inexpensive disk diffusion method, which is suitable for the analysis of a small number of isolates, as normally occurs in clinical laboratories, was evaluated as an alternative to the E test to discriminate between susceptible and resistant isolates of Bacteroides fragilis. Although this method has not yet been standardized for $B$. fragilis, the results of different studies on facultative bacteria have shown that there is a good correlation of the disk diffusion method with E-test. For example various researches conducted such a comparison between these two methods on different bacteria such as Helicobacter pylori (22), Campylobacter spp. (23), Staphylococcus aureus (24), coagulase-negative staphylococci (25), Stenotrophomonas maltophilia (26), and Escherichia coli (27).

Disk diffusion method has also been conducted on some fast-growing anaerobic bacteria and susceptibility criteria for some antibiotics have been provided (18). In the research that Barry, et al. performed on anaerobic bac- teria, disk diffusion method was reported to be appropriate and useful for fast growing anaerobic bacteria such as $B$. fragilis (11). Other researches performed this method using vancomycin and metronidazole disks on C. difficile isolates and observed a good agreement with $\mathrm{E}$ tests results (28). Dubois and Pechere have reached a strong correlation between the results of the disc diffusion for anaerobic bacteria in comparison with results reported by agar dilution method using cephalothin, cefamandole, cefazolin, and cefoxitin antibiotic discs. But the results were not satisfactory for cephalothin against B. fragilis (29). On the other hand in the study of Tally et al., the assessment of anaerobic sensitivity toward antibiotics by disc diffusion method was not declared satisfactory (12).

In 2001, the conditions to use the disk diffusion test for fast growing anaerobic such as B. fragilis and also detailed criteria for certain antibiotics such as penicillin, clindamycin and metronidazole were reported by King et al. ( 18 ). In this study results of sensitivity tests with agar disk diffusion in comparison with $\mathrm{E}$ test on B. fragilis isolated from patients and healthy people were reported. The results showed significant correlation between these two methods for some antibiotics such as imipenem, piperacillin/tazobactam, metronidazol, ciprofloxacin, chloramphenicol, rifampin and gentamicin; while, there was no significant correlation in others (Table 1). The obtained results for anaerobes by disk diffusion method indicated that this method is not satisfactory for all antibiotics.

We hence concluded that B. fragilis isolated from patients with diarrhea contain bft gene, but its presence in different isolates would not certainly result in diarrhea among patients. There is not enough accordance between DDM and Swedish E test susceptibility results of B. fragilis for some antibiotics, although in other cases a good agreement was observed. Therefore the results of DDM for anaerobes even for fast growing anaerobe bacteria such as B. fragilis should be confirmed by other reliable ones like Swedish E test or agar dilution methods.

\section{Acknowledgements}

This research was supported by a grant from Infectious \& Tropical Disease Research Center of Tabriz University of Medical sciences (TUMS), and the manuscript was written based on a dataset of MSc thesis, registered in Tabriz University of Medical Sciences. The authors would like to thank Imam Reza Medical Center Laboratory Staffs for their help. The Ethic Commission of Tabriz University of Medical Sciences approved this study.

\section{Authors' Contribution}

None Declared.

\section{Financial Disclosure}

None declared. 


\section{Funding/Support}

None declared.

\section{References}

1. Wexler HM. Bacteroides: the good, the bad, and the nitty-gritty Clin Microbiol Rev. 2007;20(4):593-621.

2. Krzyzanowsky F, Avila-Campos MJ. Detection of non-enterotoxigenic and enterotoxigenic Bacteroides fragilis in stool samples from children in Sao Paulo, Brazil. Rev Inst Med Trop Sao Paulo. 2003;45(4):225-7.

3. Kato N, Kato H, Watanabe K, Ueno K. Association of enterotoxigenic Bacteroides fragilis with bacteremia. Clin Infect Dis. 1996;23 Suppl 1:S83-6.

4. Goldstein EJ, Citron DM. Resistance trends in antimicrobial susceptibility of anaerobic bacteria, part I. Clin Microbiol Newsletter. 2011;33(1):1-8.

5. Methods for antimicrobial susceptibility testing of anaerobic bacteria. Clinical and Laboratory Standards Institute. 2004.

6. Performance standards for antimicrobial susceptibility testing. Clinical and Laboratory Standards Institute. 2011.

7. Fritsche TR, McDermott PF, Shryock TR, Walker RD, Morishita TY Agar dilution and disk diffusion susceptibility testing of Campylobacter spp. J Clin Microbiol. 2007;45(8):2758-9.

8. Ge B, Bodeis S, Walker RD, White DG, Zhao S, McDermott PF, et al. Comparison of the Etest and agar dilution for in vitro antimicrobial susceptibility testing of Campylobacter. J Antimicrob Chemother. 2002;50(4):487-94.

9. Engberg J, Neimann J, Nielsen EM, Aerestrup FM, Fussing V. Quinolone-resistant Campylobacter infections: risk factors and clinical consequences. Emerg Infect Dis. 2004;10(6):1056-63.

10. Luber P, Bartelt E, Genschow E, Wagner J, Hahn H. Comparison of broth microdilution, E Test, and agar dilution methods for antibiotic susceptibility testing of Campylobacter jejuni and Campylobacter coli. JClin Microbiol. 2003;41(3):1062-8.

11. Barry AL, Fuchs PC, Gerlach EH, Allen SD, Acar JF, Aldridge KE, et al. Multilaboratory evaluation of an agar diffusion disk susceptibility test for rapidly growing anaerobic bacteria. Rev Infect Dis. 1990;12 Suppl 2:S210-7.

12. Tally FP, Armfield AY, Dowell VR, Jr, Kwok YY, Sutter VL, Finegold SM. Susceptibility of Clostridium ramosum to antimicrobial agents. Antimicrob Agents Chemother. 1974;5(6):589-93.

13. Fader RC, Mahon CR, Lehman DC, Manuselis G. Anaerobes of clinical importance. In: Fader RC, Mahon CR, Lehman DC, Manuselis G, editors.Text Book of Diagnostic Microbiology.2011. p. 502-38.

14. Ferreira Débora Paula, Silva Vânia Lúcia, Guimarães Danielle Aparecida, Coelho Cíntia Marques, Zauli Danielle Alves Gomes, Farias Luiz Macêdo, et al. Distribution, detection of enterotoxigenic strains and antimicrobial drug susceptibility patterns of Bacteroides fragilis group in diarrheic and non-diarrheic feces from Brazilian infants. Brazilian J Microbiol. 2010;41(3):603-611.

15. Nakano V, Gomes TA, Vieira MA, Ferreira Rde C, Avila-Campos MJ bft gene subtyping in enterotoxigenic Bacteroides fragilis isolated from children with acute diarrhea. Anaerobe. 2007:13(1):1-5.

16. Pantosti A, Malpeli M, Wilks M, Menozzi MG, D'Ambrosio F. Detection of enterotoxigenic Bacteroides fragilis by PCR. J Clin Micro- biol. 1997;35(10):2482-6.

17. Justesen US, Matuschek E, Kahlmeter G. The EUCAST MuellerHinton fastidious agar for antimicrobial susceptibility testing of anaerobic bacteria? 21st European Congress of Clinical Microbiology and Infectious Diseases (ECCMID) and 27th International Congress of Chemotherapy (ICC) Milan ; Italy. 2011.

18. King A. Recommendations for susceptibility tests on fastidious organisms and those requiring special handling. J Antimicrob Chemother. 2001;48 Suppl 1:77-80.

19. Miranda KR, Dias MF, Guimaraes PL, Boente RF, Pauer H, Ramos $\mathrm{PZ}$, et al. Enterotoxigenic and nontoxigenic Bacteroides fragilis strains isolated in Brazil. Mem Inst Oswaldo Cruz. 2008;103(7):7345.

20. Pantosti A, Menozzi MG, Frate A, Sanfilippo L, D'Ambrosio F, Malpeli M. Detection of enterotoxigenic Bacteroides fragilis and its toxin in stool samples from adults and children in Italy. Clin Infect Dis. 1997;24(1):12-6.

21. Obuch-Woszczatynski P, Wintermans RG, Van Belkum A, Endtz $\mathrm{H}$, Pituch H, Kreft D, et al. Enterotoxigenic Bacteroides fragilis (ETBF) strains isolated in The Netherlands and Poland are genetically diverse. Pol J Microbiol. 2004;53(1):35-9.

22. Lang L, Garcia F. Comparison of E-test and disk diffusion assay to evaluate resistance of Helicobacter pylori isolates to amoxicillin, clarithromycin, metronidazole and tetracycline in Costa Rica.Int JAntimicrob Agents. 2004;24(6):572-7.

23. Murati Y, Ersin I, Burcu A, Nilgun U. Comparison of Disc diffusion and E test for in vitro antimicrobial susceptibility testing of Campylobacter jejuni and Campylobacter coli isolated from poultry. Revue Méd Vét. 2005;156(10-15).

24. Somily AM, Peaper DR, Paintsil E, Murray TS. Comparison of Disk Diffusion and Etest Methods to Determine the Susceptibility of Staphylococcus aureus Circulating in Riyadh, Saudi Arabia to Fusidic Acid. Int J Microbiol. 2012;2012:391251.

25. Haghi Ashtiani MT, Aboutorabi SK, Mahjoub F, Mamishi S, Asgari F. Comparison of Disk diffusion and E test methods for antimicrobial susceptibility testing of vancomycin in coagulase negative Staphylococcus isolated from blood culture. Iran J Pathol. 2008;3(2):61-66.

26. Nicodemo AC, Araujo MR, Ruiz AS, Gales AC. In vitro susceptibility of Stenotrophomonas maltophilia isolates: comparison of disc diffusion, Etest and agar dilution methods. JAntimicrob Chemother. 2004;53(4):604-8.

27. Erfani Y, Rasti A, Rezaee M, Jafari S. Comparison of Iranian disc diffusion agar and epsilometer test (E-test) accuracy, in antibiotic susceptibility of Escherichia coli isolated from patients with urinary tract infection. African J Microbiol Res. 2012;6(14):3571-3573.

28. Wong SS, Woo PC, Luk WK, Yuen KY. Susceptibility testing of Clostridium difficile against metronidazole and vancomycin by disk diffusion and Etest. Diagn Microbiol Infect Dis. 1999;34(1):1-6.

29. Dubois J, Pechere JC. Anaerobic bacteria: evaluation of disc susceptibility to four cephalosporins. Infection. 1978;6(6):266-70.

Please cite this paper as: Akhi MT, Ghotaslou R, Shirinzadeh M, Pirzadeh T, Naghavi Behzad M. Comparison of Etest and Disk Diffusion Test for Antibiotic Resistance Testing of Enterotoxigenic and Non- Enterotoxigenic Bacteroides Fragilis Isolated from Stools. Jundishapur J Microbiol. 2013;6(5): e9800. DOI: 10.5812/jjm.9800. 